\title{
Article
}

\section{Detection of anxiety disorders in Primary Care: a meta-analysis of assisted and unassisted diagnoses}

Elena Olariu ${ }^{1,2,3}$, Carlos G.Forero ${ }^{2,3}{ }^{*}$, José-Ignacio Castro-Rodriguez ${ }^{1,2,4}$, Maria Teresa Rodrigo Calvo ${ }^{1}$,

Pilar Álvarez ${ }^{4}$, Luis Miguel Martín-López ${ }^{4}$, Alicia Sánchez-Toro ${ }^{1}$,Núria D. Adroher ${ }^{2}$, Maria Jesus Blasco Cubedo $^{2}$, Gemma Vilagut ${ }^{1,2}$, Miquel A. Fullana ${ }^{4}$, Jordi Alonso ${ }^{1,2,3}$

${ }^{1}$ Universitat Pompeu Fabra (UPF), Department of Experimental and Health Sciences

${ }^{2}$ Health Services Research Unit, IMIM - Institut Hospital del Mar d'Investigacions Mèdiques

${ }^{3}$ CIBER Epidemiología y Salud Pública (CIBERESP)

${ }^{4}$ Institut de Neuropsiquiatria i Addiccions, Parc de Salut Mar, Barcelona

Funding: This study was funded by a grant from the Spanish Ministry of Health, Instituto de Salud Carlos III, FEDER PI10/00530, Fondo de Investigación Sanitaria ISCIII (FI11/00154), and by DIUE Generalitat de Catalunya (2014 SGR 748)

The authors declare that there are no conflicts of interest.

${ }^{*}$ Correspondence author: Carlos G. Forero

Carrer del Doctor Aiguader, 88, Edifici PRBB, 08003 Barcelona, Spain.

Tel. +34 933160 747; Fax: +34 933160 410; e-mail address: cgarcia@imim.es;

Short title: Diagnosing anxiety disorders in Primary Care

Keywords: Anxiety Disorders; Primary Care; Assessment/Diagnosis; Sensitivity; Specificity. 


\title{
Detection of anxiety disorders in Primary Care: a meta-analysis of assisted and unassisted diagnoses
}

\begin{abstract}
Background: Evidence suggests that general practitioners (GPs) fail to diagnose up to half of common mental disorder cases. Yet no previous research has systematically summarized the evidence in the case of anxiety disorders. The aim of this review was to systematically assess and meta-analyze the diagnostic accuracy of GPs' assisted (i.e., using severity scales/diagnostic instruments) and unassisted (without such tools) diagnoses of anxiety disorders.
\end{abstract}

Methods: Systematic review (PROSPERO registry CRD42013006736). Embase, Ovid Journals - Ovid SP Medline, Pubmed, PsycINFO, Scopus, Web of Science, and Science Direct were searched from January 1980 through June 2014. Seven investigators, working in pairs, evaluated studies for eligibility. The quality of included studies was assessed with the Quality Assessment of Diagnostic Accuracy Studies tool version 2 (QUADAS-2). The main outcome measures were sensitivity and specificity of clinical diagnoses of any anxiety disorder. We pooled sensitivity and specificity levels from included studies using bivariate meta-analyses.

Results: 24 studies were included in the meta-analysis with a total sample of 34,902 patients. Pooled sensitivity and specificity were estimated at $44.5 \%(95 \% \mathrm{CI}=33.7 \%-55.9 \%)$ and $90.8 \%(95 \% \mathrm{CI}=87 \%$ 93.5\%). GPs' sensitivity was higher when diagnoses were assisted $(63.6 \%, 95 \% \mathrm{CI}=50.3 \%-75.1 \%)$ than when unassisted $(30.5 \%$; $95 \% \mathrm{CI}=20.7 \%-42.5 \%)$ to the expense of some specificity loss $(87.9 \%$; $95 \%$ $\mathrm{CI}=81.3 \%-92.4 \%$ vs. $91.4 \% ; 95 \% \mathrm{CI}=86.6 \%-94.6 \%$, respectively). Identification rates remained constant over time ( $\mathrm{p}$-value $=0.998)$. 
Conclusions: The use of diagnostic tools might improve detection of anxiety disorders in Primary Care. 
Detection of anxiety disorders in Primary Care: a meta-analysis of assisted and unassisted diagnoses

\section{INTRODUCTION}

Anxiety disorders are commonly diagnosed in primary health care (PHC) settings ${ }^{[1]}$, with 12-month prevalence rates varying from $8 \%$ to $20 \%{ }^{[2-6]}$.

This group of disorders is associated with impaired quality of life and compromised psychosocial functioning ${ }^{[7]}$, and the disability they cause is comparable to that of chronic physical illnesses like diabetes and hypertension ${ }^{[8]}$. They have an early onset ${ }^{[9,10]}$ and a tendency toward chronicity ${ }^{[1]}$ with high comorbidity rates ${ }^{[12]}$. Additionally, they generate a great economic burden with total costs estimated at $€ 74.4$ billion or $\$ 97.4$ billion (currencies converted using Purchasing Power Parity $2010^{[13]}$ ) at European level ${ }^{[14]}$.

Despite the high prevalence of anxiety disorders in PHC settings, general practitioners (GPs) still find it challenging to diagnose anxiety disorders ${ }^{[15]}$, with several studies reporting low percentages of correct anxiety disorder diagnoses in Primary Care ${ }^{[16-18]}$. Identification rates for anxiety disorders in Primary Care can be less than $50 \%{ }^{[19,20]}$, with only one third of anxiety cases being correctly diagnosed ${ }^{[21]}$ and with only $33-64 \%$ of patients with an anxiety disorder receiving an accurate specific diagnosis ${ }^{[22]}$. While the recognition rate for panic disorder without and with agoraphobia is relatively high (53 and 64\% respectively), the recognition rate for generalized anxiety disorder (GAD), the most prevalent anxiety disorder in Primary Care, is only $33 \%{ }^{[22]}$.

Furthermore, low rates of quality care have been reported in patients with anxiety disorders in PHC settings, with fewer than $10 \%$ receiving appropriate psychotherapy and with only $25 \%$ receiving antianxiety medications at a minimally adequate dose and duration ${ }^{[23]}$. Overall, two out of three patients had not received adequate psychotherapy or pharmacotherapy. When left undiagnosed and subsequently 
untreated, anxiety disorders can become associated with suicidal behavior ${ }^{[24]}$. Additionally, patients with undetected anxiety disorders may also undergo unnecessary, costly and potentially invasive diagnostic investigations $^{[25]}$ (e.g. coronary angiographies) ${ }^{[26,27]}$, as well as unnecessary referrals to specialists (e.g., gastroenterologists, cardiologists) or visits to emergency departments in an attempt to identify nonexistent organic disorders ${ }^{[28,29]}$. Conversely, if correctly diagnosed, anxiety disorders can be treated effectively in PHC settings ${ }^{[30]}$. This can lead to lowered healthcare costs derived from a less frequent use of healthcare resources ${ }^{[31]}$ and improved clinical outcomes due to a reduction in the duration of untreated illness ${ }^{[32]}$. Additionally, if correct diagnosis is followed by proper adherence to clinical guidelines, $35 \%$ of the economic burden of anxiety disorders can be averted ${ }^{[33]}$.

Even though some anxiety disorders can sometimes be more chronic and more impairing than mood disorders ${ }^{[25]}$, less systematic research is available on management and diagnosis of anxiety disorders in PHC compared to other mental disorders ${ }^{[19]}$. In fact, to our knowledge, no systematic reviews assessing the diagnostic accuracy of GPs' diagnoses of anxiety disorders have been performed so far. An improved understanding of GPs' diagnostic accuracy of anxiety disorders is a fundamental step in building better access to care and treatment for patients with anxiety disorders in PHC. Anxiety scales may help GPs to detect specific anxiety disorders ${ }^{[34,35]}$, but evidence of the added value of their use over routine clinical judgment is limited. We, therefore, performed a systematic review of data on accuracy of assisted and unassisted diagnoses of anxiety disorders by GPs, worldwide, in adults and children/adolescents. We considered assisted diagnoses as diagnoses made with the help of severity scales or other diagnostic instruments and unassisted diagnoses as diagnoses made without such tools. We hypothesized that GPs' diagnostic accuracy would be higher when conducting assisted clinical interviews given that the use of clinical scales or instruments is recommended by certain clinical guidelines as a way to reinforce and guide the practitioner's clinical judgment ${ }^{[36]}$.

\section{METHODS}


This review was conducted following the guidelines of the Cochrane Handbook for Systematic Reviews of Diagnostic Test Accuracy. A protocol was registered in PROSPERO (International Prospective Register of Systematic Reviews), under the registration number CRD42013006736.

\section{Search strategy}

We searched for articles from January 1980 to June 2014 in the following internet databases: Embase, Ovid Journals - Ovid SP Medline, Pubmed, PsycINFO (via EBSCO), Scopus, Web of Science, and Science Direct. The search terms included "anxiety disorder", "diagnosis" and "Primary Care", as controlled vocabulary and as free text. The search was initially designed in Embase and then translated to the remainder of the databases (see annex I). We also manually searched for citations in reference lists of all included articles.

\section{Eligibility criteria and selection of studies}

We included studies that reported on the ability of GPs to identify any anxiety disorder. Our definition of "any anxiety disorder" included the following disorders: panic disorder with or without agoraphobia, agoraphobia without history of panic disorder, specific phobia, social anxiety disorder, obsessive compulsive disorder, generalized anxiety disorder, anxiety disorder not otherwise specified. Subsequently, only articles that provided estimable results on measures of diagnostic accuracy in Primary Care patients were included. We also considered any type of mental disorder diagnostic procedure: based on anamnesis (unassisted, where the practitioner tries to make a diagnosis without any help from severity scales or diagnostic instruments) or assisted (where the practitioner tries to diagnose anxiety disorders with the help of any type of questionnaire or scale). Nevertheless, either assisted or unassisted, the final decision regarding the diagnosis belonged to the GP. Articles written in English, Spanish, French and German were included. 
As we had an interest only in routine Primary Care attenders, we excluded studies in general population samples and studies whose Primary Care patients were selected because of a specific physical pathology or a previous or suspected diagnosis of anxiety disorders. We also excluded vignette studies and case/case-series report studies.

\section{Data extraction}

Seven members of the research team: three psychiatrists (PA, JIC, LML), two psychologists (CGF, MJBC), one pharmacist (EO) and one sixth year medical student (MR), working in pairs, independently reviewed studies found in the literature searches by examining eligibility criteria for titles and abstracts. Discrepancies were solved through consensus or by a third reviewer. Exclusion codes were defined and registered for abstract and full-text steps. A pilot test was performed in order to homogenize criteria among reviewers. We also manually examined the reference lists of all included articles.

Data were extracted by one reviewer (EO) using a standard data extraction form and verified by a second reviewer (CGF). Any disagreements were resolved through consensus or third party adjudication, if needed. We extracted data for the following categories: study characteristics (design, main objective, country of origin, study year), participant characteristics (sample size, sex, age), GPs characteristics (number of participating GPs, age, years of clinical experience, sex, size and area of the Primary Care centre), diagnostic characteristics (source of diagnostic information, method of diagnosis, type of visit, diagnostic reference standard and criteria), and measures of diagnostic accuracy (sensitivity, specificity, prevalence, contingency table). We contacted study authors if further clarification was needed.

We assessed the quality of the included articles with QUADAS-2 tool ${ }^{[37]}$ following the recommendations of the Cochrane Collaboration and of the U.K National Institute for Health and Clinical Excellence $^{[38]}$. The quality of included studies, as determined by QUADAS-2, firstly entails evaluating whether the diagnostic accuracy estimates reported by the studies are free from bias (risk of bias), and secondly entails measuring the degree to which primary studies are relevant to the review's research 
question (applicability). This tool comprises four domains: patient selection, index test, reference standard, and flow of patients through the study and timing of the index tests and reference standard (flow and timing). The patient selection domain evaluates, in terms of risk of bias and applicability, the methods used to select patients: type of sampling, design, exclusions made and characteristics of included patients. The index test domain determines whether the results of the index test were interpreted without knowledge of the results of the reference standard (e.g. the GPs made their diagnoses without knowing the results of the reference standard), as well as whether its conduct or interpretation varied from the ones specified in the review question. The reference standard domain assesses whether the diagnostic reference standards used in the included studies correctly classify the target disorder (anxiety disorders), if a blinded administration was used and also if "target disorder" (anxiety disorder), as defined by the diagnostic reference standard, matched the review question. The flow and timing domain tries to establish whether all patients were included in the analysis and if they all received the same reference standard.

Additionally, it determines if an adequate interval of time has elapsed between the administration of the diagnostic reference standard and the index test ${ }^{[37]}$.

Each domain is judged as having "low", "high" or "unclear" risk of bias, as well as "low", "high" or "unclear" concerns about applicability. There is no overall quality score.

\section{Statistical analysis}

Whenever possible, we used the studies' reported measures of diagnostic accuracy. If this information was not provided, we constructed contingency tables using the available data. Coupled forest plots were used to report the estimated sensitivity and specificity, together with confidence intervals, in each study.

Given that heterogeneity is always to be expected in meta-analyses of diagnostic accuracy, we fitted random-effects meta-analysis models ${ }^{[39]}$. We undertook a bivariate meta-analysis. This approach preserves the two-dimensional nature of the data by analyzing together pairs of sensitivity and specificity ${ }^{[40]}$. Additionally, it incorporates any potential (negative) correlation that might exist between sensitivity 
and specificity within studies by using a random effects approach ${ }^{[40]}$. The parameters of the bivariate distribution were used to calculate summary estimates of sensitivity and specificity and to estimate a summary Receiver Operating Characteristic (sROC) curve. Around the summary estimates of sensitivity and specificity, we also plotted $95 \%$ confidence and prediction regions. The $95 \%$ confidence region illustrates the precision with which the summary values of sensitivity and specificity were estimated. It is drawn as an ellipse around the mean values of sensitivity and specificity. $95 \%$ prediction regions show the amount of between-study variation, reflecting the range of likely values for an individual study. They plot the particular probability of including the true sensitivity and specificity of a future study.

AUCs for the overall, assisted and unassisted pooled estimates were computed using the sROC approach with the bivariate method ${ }^{[41]}$, under the assumption of homogeneous sROC curves for computing AUCs and confidence intervals ${ }^{[40]}$.

We investigated heterogeneity by adding the following covariates: method of diagnosis, type of anxiety disorder, type of reference standard, type of instrument used, year of publication, country of origin, funding sources, objective of the study, age, disorder prevalence and specific QUADAS-2 items that raised concerns (risk of bias for patient, reference standard and flow domains, patient applicability, reference standard acceptability and blinding of the index test and reference standard). Heterogeneity was assessed with a bivariate model by including in the model each covariate at a time and testing its statistical significance with the likelihood ratio test. All analyses were run with SAS v9.1.2, with the macro MetaDAS (Proc NLMIXED) developed by The Cochrane Collaboration ${ }^{[39]}$.

\section{RESULTS}

After title review and duplicates removal, a total of 3.424 abstracts were found through database searching. Figure 1 displays the selection of studies for the meta-analysis and the exclusion reasons for every step of the review. Approximately $80 \%$ of the retrieved references, at both abstract and full-text steps, were excluded because they did not report sensitivity and specificity levels for GPs' diagnoses of 
anxiety disorders. Finally, 27 articles met the eligibility criteria. Review of all the reference lists of all included articles lead to two additional papers meeting all eligibility criteria. Finally, 24 articles (one article reporting data on both assisted and unassisted diagnoses) were included in the meta-analysis as five papers reported data already contained in previously included publications.

$$
\text { --- Figure } 1 \text { about here ----- }
$$

\section{Quality Assessment}

Based on QUADAS-2 assessment (see Figure 2), only five of the included studies were found to have a low risk of bias in all 4 domains. The domain most susceptible to bias was the one assessing the reference standard, its interpretation and its likelihood to correctly classify anxiety disorders in case of 10 studies. 7 studies did not use an adequate reference standard and additionally the results of the reference standard were interpreted knowing the GP diagnosis in the case of two articles ${ }^{[42,43]}$. Concerns regarding applicability were raised by the selection of patients in one article ${ }^{[44]}$ where the included sample oversampled cases that screened positive at the first stage of the Primary Care Evaluation of Mental Disorders (PRIME-MD) administration (92.40\% positive screen cases included in the final sample).

\section{Study Characteristics}

Most of included studies were conducted in Europe and in the early years of the $21^{\text {st }}$ century (see Table 1). Determining the accuracy of GPs' diagnoses of anxiety disorders was the main research objective in case of $41.7 \%$ of included studies. 19 studies had information on funding sources with $42.1 \%$ having being funded by a pharmaceutical company. $52.2 \%$ of the included studies gave information on unassisted diagnoses of anxiety disorders in Primary Care.

The total pooled sample was 34,902 patients with a mean sample size of 1,396 per study $(\mathrm{SD}=$ 3,494.6). The mean age of included patients, estimated from available data, was around 48.8 years $(\mathrm{SD}=$ 6.94). $60.2 \%$ of included patients were women ${ }^{[16,18,34,42-57]}$ and $59.9 \%$ were either married or living with a partner ${ }^{[18,34,42,44,46,47,49,51,54-57]}$. The recruited sample consisted entirely of new patients or patients with a new health problem in case of two studies ${ }^{[46,53]}$. Another study reported that all included patients had no previous history of mental disorders ${ }^{[48]}$ and in one US study $77 \%$ of the recruited individuals were established Primary Care patients ${ }^{[20]}$. 
Only two studies ${ }^{[45,49]}$ reported the age profile of participating GPs and the mean estimated age was 45.8 years. The GPs' clinical experience varied from 10.3 years ${ }^{[53]}$ to 17.8 years $(\mathrm{SD}=9.6)^{[50]}$. A total of 1,691 GPs participated in the studies with most of the Primary Care Centres being located in urban areas [22,44,47,48,54-56,58,59] . Only one study reported having included Primary Care Centres from both urban and rural areas ${ }^{[49]}$. GPs' workload was reported in two studies ${ }^{[18,34]}$ and it varied from 21.1 patients seen per day to 61.

The prevalence of anxiety disorders varied from a very low $1.5 \%{ }^{[57]}$ to a very high $50.3 \%{ }^{[55]}$ with a median value of $16.4 \% .69 \%$ of included studies reported data on anxiety disorders in general, with only 9 tackling a specific anxiety subtype. Out of the 20 studies presenting data on anxiety disorders three ${ }^{[16,20,47]}$ reported results on specific subtypes of anxiety disorder as well. In terms of design, the great majority of studies were cross-sectional. Only one study was a clinical trial.

\section{Main Findings}

----- Table 1 about here -------

Figure 3 shows the forest plot of all included studies. Results from the Christensen et al study (FIP study) ${ }^{[53]}$ were included as two different estimators because one arm of the clinical trial reported data for assisted diagnoses of anxiety disorders and the other arm for unassisted diagnoses of anxiety disorders in Primary Care. Sensitivity levels varied from a low $9 \%$ to a high $90 \%$, whereas observed estimates of specificity were more homogeneous with a low $67 \%$ and a high $99 \%$.

Figure 3 about here

Figure 4.A shows the summary ROC curve of all included studies with a pooled estimate of sensitivity of $44.5 \%(95 \%$ CI $33.7 \%-55.9 \%)$ and of specificity of $90.8 \%(95 \%$ CI $87 \%-93.5 \%)$. The estimated AUC was 0.802 ( $\mathrm{SE}=0.027)$.

Assisted diagnoses were more accurate than unassisted diagnoses (Sensitivity: 63.6\%, 95\% CI 50.3\% - 75.1\%; Specificity: $87.9 \%$, 95\% CI 81.3\% - 92.4\% vs Sensitivity: 30.5\%, 95\% CI 20.7\% - 42.5\%; Specificity: 91.4\% 95\% CI 86.6\% - 94.6\%; p-value=0.031) (see Figure 4.B). The AUC for assisted diagnoses was higher than the one registered for unassisted diagnoses ( $\mathrm{AUC}{ }_{\text {assisted }}=0.85, \mathrm{SE}=0.03 \mathrm{vs}$. $\left.\mathrm{AUC}_{\text {unassisted }}=0.73, \mathrm{SE}=0.04\right)$.

In case of assisted diagnoses no association was found between diagnostic accuracy and the type of instrument used ( $p$-value $=0.2$ ). The variable type of instrument was grouped in three categories: 
diagnostic (The Mini-International Neuropsychiatric Interview - MINI, The Symptom Driven Diagnostic System for Primary Care - SDDS-PC, Primary Care Evaluation of Mental Disorders - PRIME-MD, TRIPS), screening (Common Mental Disorder Questionnaire - CMDQ, Social Anxiety Screening Questionnaire - SAS-Q, case finding questions) or severity scale (Clinical Global Impressions Scale CGI-S). Still, the results of this analysis should be interpreted with caution as the number of studies in certain categories of the variable type of instrument was rather small.

95\% confidence and prediction regions are shown in both Figure 4.A and Figure 4.B. Prediction regions are larger than confidence regions in both figures reflecting high heterogeneity between studies. ------ Figures 4.A and 4.B about here -------

Diagnostic sensitivity was higher in studies funded by pharmaceutical companies $(63.4 \%, 95 \% \mathrm{CI}$ $49.1 \%-75.7 \%$ vs. $28.6 \%$, $95 \%$ CI $20.2 \%$ - 38.9.2\%, p-value $=0.01$ ). Mean patient age was significantly associated with diagnostic accuracy, with a decrease of 0.3 in sensitivity levels for each year increase in age $(p-$ value $=0.001)$. No significant associations were found between diagnostic accuracy and type of anxiety disorder, disorder prevalence, DSM-defined or no DSM-defined reference standard, year of publication, country of origin (grouped as high \& low/middle income countries) and objective of the study (objective focused on diagnostic accuracy assessment or not). When assessing QUADAS-2 related covariates as possible sources of heterogeneity, none of them was found to be statistically significant. We also investigated the existence of a possible association between diagnostic accuracy and a categorical variable that considered both the use of DSM-defined or no DSM-defined reference standards and method of diagnosis, and again no statistically significant difference was found ( $p$-value $=0.304$ ).

\section{DISCUSSION}

Diagnosing anxiety disorders at non-specialized health care levels can be a challenging task ${ }^{[60]}$. The results of the present review show that, when diagnosing anxiety disorders, GPs' sensitivity (i.e. the ability to correctly classify an individual as "diseased") is low (44.5\%) while their ability to correctly identify non-cases as not having the disorder is high (specificity $90.8 \%$ ). Our results are similar to the ones Mitchell et al ${ }^{[61]}$ found for depression in Primary Care: sensitivity $50.1 \%$ and specificity $81.3 \%$. 
They are also in line with other summary estimates of sensitivity of other mental disorders in Primary Care: GPs diagnostic sensitivity for alcohol use disorders was estimated at 41.7\%, 95\% CI 23.0-61.7 ${ }^{[62]}$. According to our findings, GPs have difficulty in diagnosing anxiety disorders in true cases. The percentage of under recognition is even higher when diagnoses are unassisted, with a drop of almost $50 \%$ in sensitivity levels with respect to assisted diagnoses. Apparently, the impact is less noticeable on specificity levels that remain practically the same irrespective of the use of questionnaires. Additionally, the level of recognition does not seem to vary with the type of anxiety disorder diagnosed. For example, in case of generalized anxiety disorder, the estimates of sensitivity and specificity obtained $(42.6 \% \%$ and $85.7 \% \%$ respectively) were very similar to the levels obtained for the rest of anxiety disorders combined (Sensitivity: 44.3\%; Specificity 91.2\%; p-value=0.445). Nevertheless, the number of studies that addressed GPs' diagnostic accuracy in different subtypes of anxiety was rather small (5 studies included in the meta-analysis). An important finding is that identification rates do not seem to change throughout the years ( $p$-value $=0.998$ ), even though during the last few years several intervention programs have been created with the purpose of improving the quality of care for anxiety disorders in Primary Care ${ }^{[63,64]}$.

Given the results of our study, strategies more focused on increasing the GPs' level of suspicion for the presence of an anxiety disorder might be beneficial. One possible solution might be the use of suitable screening instruments, as is the case with depression in the UK and US where screening is recommended by national guidelines ${ }^{[65,66]}$. Several instruments for screening for anxiety disorders in Primary Care settings have been developed and used with adequate results ${ }^{[67,68]}$. Screening for anxiety disorders in Primary Care can be a useful way to enhance recognition of these disorders and improve treatment rates and patients care ${ }^{[69]}$. Screening tools could allow identifying "high-likelihood" cases, saving an exhaustive clinical evaluation (more costly and time-consuming) for patients with a positive screen.

However, routine screening of all patients for the presence of anxiety symptoms is not recommended ${ }^{[70]}$. Other approaches have been suggested like screening for anxiety disorders only in high-risk primary 
care patients ${ }^{[71]}$ or using case finding strategies to help the GP distinguish distress symptoms from an anxiety disorder, as the current Dutch guidelines for anxiety recommend ${ }^{[72]}$.

Nevertheless, screening for anxiety disorders is necessary, but not sufficient to improve the quality of mental health care and outcomes among Primary Care patients with anxiety disorders ${ }^{[73]}$. Several studies have shown that quality of care and outcomes improve only when screening is associated with multimodel intervention programs like collaborative care ${ }^{[74,75]}$, thus when accompanied by other changes in practice structure.

\section{Possible explanations for our findings}

Our results must be interpreted keeping in mind the particular characteristics of Primary Care. Several factors, including patient, provider and system barriers have been identified as possible problems to higher detection rates of mental disorders in Primary Care. First of all, patients might resist disclosing anxiety symptoms, either due to beliefs that personal weaknesses are the cause of their problems ${ }^{[76]}$ or that pharmacological treatments ${ }^{[77]}$ are harmful or simply because cultural barriers impede them to admit they suffer psychological distress ${ }^{[78]}$. Additionally, patients often present with somatic rather than emotional complaints ${ }^{[79,80]}$, and attribute more easily their symptoms to physical causes ${ }^{[81]}$.

From the provider end, different aspects can act as a barrier to adequate recognition or treatment. These include, for example, GPs' deficient knowledge of the diagnostic procedure ${ }^{[82]}$, potential inability to read nonverbal cues ${ }^{[83]}$, or interview styles not encouraging psychosocial disclosure. Additionally, limited appointment times with little time for patient education and counseling ${ }^{[84]}$, concerns about potential patient stigma or the common belief that such diagnoses are burdensome ${ }^{[85]}$ have also been pointed as potential reasons for lower recognition rates. Furthermore, physicians' beliefs and attitudes towards mental disorders have substantial influence on detection rates with lower levels in case of practitioners with negative opinions and attitudes ${ }^{[83]}$. 
Although simplified and specifically adapted for Primary Care, the World Health Organization (WHO) ICD-10 Primary Health Care (PHC) Guidelines for Diagnosis and Management of Mental Disorders are sometimes impractical for routine use and have uncertain impact on clinician behavior ${ }^{[86,87]}$. Other system barriers include productivity pressures, the lack of a systematic method for managing patients with common mental disorders ${ }^{[88]}$ and inadequate continuity of care ${ }^{[89]}$.

\section{Limitations and strengths}

Our results should be interpreted in the light of several limitations. Most of the studies included in our review were cross-sectional with only 3 studies reporting a longitudinal GP assessment ${ }^{[16,50,57]}$. Given the fact that assessments in Primary Care have a clear longitudinal component, we cannot be sure that the disorder will not be diagnosed at a later date ${ }^{[90]}$ and that diagnostic accuracy would eventually increase. Future research should focus more on longitudinal assessment of anxiety disorders in Primary Care and also indicate, at the same time, whether undetected anxiety is important clinically, or whether it causes disability or remains undetected.

Our definition of "any anxiety disorder" did not include post-traumatic stress disorder (PTSD). We considered that the mandatory identification of a stressor/traumatic event or other causes external to the individual separated these patients into a distinctive subgroup, with a particular vulnerability.

Additionally, most PTSD studies in Primary Care were conducted on veteran populations ${ }^{[1]}$ who are mainly attended in Veterans Affairs primary care clinics, a setting different from the general primary care. Furthermore, in general primary care samples, lower prevalence rates of PTSD have been reported ${ }^{[22]}$. Additionally, PTSD assessment of potential stressors, as defined before DSM-V, is not a strategy with high specificity when conducted retrospectively and with little relevance for establishing a probable PTSD diagnostic ${ }^{[93]}$.

Moreover, we could not adjust our results for the effect of severity of anxiety disorders, which is known to be strongly associated with detection accuracy, as only one study ${ }^{[50]}$ reported levels of disorder 
severity in the recruited sample. Adjustment for comorbidity with depression, a frequent occurrence found in Primary Care ${ }^{[94]}$, was not possible either, because only two studies ${ }^{[50,52]}$ reported data on comorbidity of anxiety with depression. Finally, stratified analyses by age (children/adolescents, adults and elderly) initially planned in the protocol could not be performed. The presentation of anxiety may differ with age, leading to challenges in identifying it ${ }^{[95]}$. For example, elderly may tend to present with more physical symptoms ${ }^{[96]}$, while children/adolescents might lack the cognitive capabilities to report details vital to the application of the diagnostic classification system ${ }^{[97]}$. Unfortunately, none of the included studies reported data exclusively on children/adolescents and only one study was conducted on the elderly ${ }^{[45]}$. Besides, the recruited sample of two studies included both adolescents and adults ${ }^{[42,47]}$ and adolescents, adults and elderly in another two studies ${ }^{[18,52]}$. Availability of more research on age stratified results for GPs diagnostic accuracy will provide better and unbiased estimates of recognition in Primary Care, enabling interventions in age groups with lowest diagnostic accuracy.

As reflected by the QUADAS-2 assessment, concerns were raised by the quality of the reference standards used by several studies. Non-optimal reference standards may bias the measurement of diagnostic accuracy of GPs diagnoses ${ }^{[98]}$. But it is not clear if they cause under- or over-estimation of diagnostic accuracy ${ }^{[98]}$. Nevertheless, we found no statistically significant association when analyzing as a possible source of heterogeneity the acceptability of the reference standard.

Also, for those studies that were industry funded, $62.5 \%$ reported data on assisted diagnoses whereas only $37.5 \%$ gave information on unassisted diagnoses. The role of the variable "funding" in biasing the results of clinical research has already been acknowledged, at multiple levels, in case of industrysponsored clinical trials ${ }^{[99]}$. Notwithstanding, a significant association was found between diagnostic sensitivity and a categorical variable that considered both funding and method of diagnosis information (Sensitivity estimate for Assisted Diagnoses Studies \& Funded by pharmaceutical companies: 68.1\%, $95 \%$ CI $56.1 \%-78.2 \%$ vs. Sensitivity estimate for Studies with unassisted diagnoses \& Funded by 
pharmaceutical companies: $58.6 \%, 95 \% \mathrm{CI} 42.7 \%$ - 72.9\% vs. Sensitivity estimate for Studies with assisted diagnoses \& Not funded by pharmaceutical companies: $43.2 \%, 95 \%$ CI $29.9 \%-57.6 \%$ vs Sensitivity estimate for Studies with unassisted diagnoses \& Not funded by pharmaceutical companies $22.7 \%, 95 \%$ CI $16.4 \%-30.5 \%$; p-value $=0.002$ ). Therefore, a risk for potential bias towards overdiagnosis cannot be excluded in studies sponsored by a drug company. Additionally, a potential interaction between funding source and method of diagnosis cannot be excluded, with studies funded by pharmaceutical companies potentially having a higher tendency of using a more rigorous and controlled methodology. Nevertheless, the number of studies in certain categories of the variable was again rather small.

Finally, the risk of diagnostic review bias cannot be fully excluded from our results, with a potential increase in the agreement between the reference standard and GPs' diagnoses. Even though we found no statistically significant associations between blinding QUADAS-2 variables and diagnostic accuracy, the number of studies in certain categories was low, potentially reducing the power to detect differences in diagnostic accuracy. For example, just two studies ${ }^{[2,43]}$ reported that the results of GPs' assessments were known when the results of the reference standard were interpreted and in case of another six it was unclear whether GPs diagnoses were blind to reference standard results ${ }^{[44,45,50,51,55,56]}$.

Nonetheless, our work has some strengths which lie on the extensive database search, the broad language inclusion criteria and long time period coverage. Additionally, sensitivity analyses showed that our findings are robust to the decisions made during the review process. The exclusion of a study whose participants characteristics did not fully meet the eligibility criteria (only 107 patients were from Primary Care) ${ }^{[56]}$ as well as that of an abstract whose results could not be confirmed in subsequent publications ${ }^{[58]}$ lead to a less than $1 \%$ change in both sensitivity and specificity levels.

\section{CONCLUSIONS}

Our data suggests that the use of adequate and brief questionnaires for case detection in Primary Care might greatly improve diagnostic accuracy, resulting in a better care for anxiety disorders in Primary 
Care. Moreover, GPs have favorable views regarding the use of diagnostic scales in their practice, with most of them believing that the diagnostic questionnaire assisted them in making at least one new diagnosis ${ }^{[100]}$. Improving detection rates in Primary Care may not necessarily lead to an overmedicalization of the matter and subsequently to an increase in the cost of care or of treatment. We hypothesize that most probably this increase would lead to a raise in the detection of mild cases in whom current guidelines recommend the use of low intensity interventions like cognitive behavior therapy, selfhelp programmes or psychoeducational groups ${ }^{[101]}$. Future research should bring more insight into the characteristics of the patients that go undetected, how they are treated and how they progress, as well as insight into the evaluation of the costs that these patients generate at healthcare systems level. Consideration should also be given to possible gender differences in both diagnostic accuracy levels and unrecognized cases.

It is undoubtedly true that diagnosis alone is not enough to improve the quality of life of these patients and that future actions should also focus on better ways to manage anxiety disorders in Primary Care with multimodal intervention programs like stepped collaborative care ${ }^{[64,101]}$. With current guidelines for depression and generalized anxiety disorder recommending treatment of the most severe problem first in case of comorbidity, steps have already been made towards a better acknowledgement of the importance of anxiety disorders in the context of other comorbid mental disorders and in other context as well. But, implementing a more balanced approach to detecting and managing anxiety in routine clinical practice takes time and it can only be done gradually. 


\section{Funding:}

This study was funded by a grant from the Spanish Ministry of Health, Instituto de Salud Carlos III, FEDER PI10/00530, Fondo de Investigación Sanitaria ISCIII (FI11/00154), and by DIUE Generalitat de Catalunya (2014 SGR 748). 


\section{Acknowledgements}

We would like to thank Alexandra Păcurariu and Wichor Bramer for their help in designing the Embase search strategy of this review. We would also like to thank Dave MacFarlane for the help provided with the citation management software. 


\section{Appendix}

The search strategy for all databases is available online at http://... 


\section{REFERENCES}

1. Toft T, Fink P, Oernboel E, et al. Mental disorders in primary care: prevalence and co-morbidity among disorders. Results from the functional illness in primary care (FIP) study. Psychol Med 2005; 35: 1175-84.

2. Qin X, Phillips MR, Wang W, et al. Prevalence and rates of recognition of anxiety disorders in internal medicine outpatient departments of 23 general hospitals in Shenyang, China. Gen Hosp Psychiatry 2010; 32: 192-200.

3. Mergl R, Seidscheck I, Allgaier A-K, et al. Depressive, anxiety, and somatoform disorders in primary care: prevalence and recognition. Depress Anxiety 2007; 24: 185-95.

4. Kroenke K, Spitzer RL, Williams JBW, et al. Anxiety disorders in primary care: prevalence, impairment, comorbidity, and detection. Ann Intern Med 2007; 146: 317-25.

5. Serrano-Blanco A, Palao DJ, Luciano J V, et al. Prevalence of mental disorders in primary care: results from the diagnosis and treatment of mental disorders in primary care study (DASMAP). Soc Psychiatry Psychiatr Epidemiol 2010; 45: 201-10.

6. Ustun TB, Sartorius N. Mental illness in general health care. Chichester, England: John Wiley \& Sons, 1995.

7. Mendlowicz M V, Stein MB. Quality of life in individuals with anxiety disorders. Am J Psychiatry 2000; 157: 669-82. 
8. Ormel J, VonKorff M, Ustun TB, et al. Common mental disorders and disability across cultures. Results from the WHO Collaborative Study on Psychological Problems in General Health Care. JAMA 1994; 272: 1741-8.

9. Kessler RC, Berglund P, Demler O, et al. Lifetime prevalence and age-of-onset distributions of DSM-IV disorders in the National Comorbidity Survey Replication. Arch Gen Psychiatry 2005; 62: 593-602.

10 . Kessler RC, Aguilar-Gaxiola S, Alonso J, et al. Lifetime Prevalence and Age of Onset Distributions of Mental Disorders in the World Mental Health Survey Initiative. Chapter 24. Part III. Cross-National Comparisons. In: Kessler RC, editor.The WHO World Mental Health Surveys: global Perspectives on the Epidemiology of Mental Disorders; 2008, p 511-21.

11. Beesdo K, Knappe S, Pine DS. Anxiety and anxiety disorders in children and adolescents: developmental issues and implications for DSM-V. Psychiatr Clin North Am 2009; 32: 483-524.

12. Kaufman J, Charney D. Comorbidity of mood and anxiety disorders. Depress Anxiety 2000; 12 Suppl 1: 69-76.

13. OECD. Prices and purchasing power parities (PPP). Available at: http://www.oecd.org/std/pricesppp/purchasingpowerparitiespppsdata.htm.

14. Gustavsson A, Svensson M, Jacobi F, et al. Cost of disorders of the brain in Europe 2010. Eur Neuropsychopharmacol 2011; 21: 718-79.

15. Culpepper L. Use of algorithms to treat anxiety in primary care. J Clin Psychiatry 2003; 64 Suppl 2: $30-3$.

16. Fernandez A, Rubio-Valera M, Bellon JA, et al. Recognition of anxiety disorders by the general practitioner: Results from the DASMAP Study. Gen Hosp Psychiatry 2012; 34: 227-33.

17. Vermani M, Marcus M, Katzman MA. Rates of detection of mood and anxiety disorders in primary care: a descriptive, cross-sectional study. Prim care companion CNS Disord 2011; 13: 18 9.

18. Wittchen HU, Kessler RC, Beesdo K, et al. Generalized anxiety and depression in primary care: prevalence, recognition, and management. J Clin Psychiatry 2002; 63 Suppl 8: 24-34.

19. Wittchen H-U, Mühlig S, Beesdo K. Mental disorders in primary care. Dialogues Clin Neurosci 2003; 5: 115-28.

20. Spitzer RL, Williams JB, Kroenke K, et al. Utility of a new procedure for diagnosing mental disorders in primary care. The PRIME-MD 1000 study. JAMA 1994; 272: 1749-56.

21 Lecrubier Y, Nutt, Kirmayer, et al. Prescribing patterns for depression and anxiety worldwide. J. Clin. Psychiatry. 2001; 62: 31-8. 
22. Weiller E, Bisserbe JC, Maier W, et al. Prevalence and recognition of anxiety syndromes in five European primary care settings. A report from the WHO study on Psychological Problems in General Health Care. Br J psychiatrySupplement 1998; 18-23.

23. Stein MB, Sherbourne CD, Craske MG, et al. Quality of care for primary care patients with anxiety disorders. Am J Psychiatry 2004; 161: 2230-7.

24. Sareen J, Cox BJ, Afifi TO, et al. Anxiety disorders and risk for suicidal ideation and suicide attempts: a population-based longitudinal study of adults. Arch Gen Psychiatry 2005; 62: 1249-57.

25. Buszewicz MJ, Chew-Graham C. Improving the detection and management of anxiety disorders in primary care. Br J Gen Pract 2011; 61: 489-90.

26. Fleet RP, Beitman BD. Unexplained chest pain: when is it panic disorder? Clin Cardiol 1997; 20: 187-94.

27. Christoph M, Christoph A, Dannemann S, et al. Mental symptoms in patients with cardiac symptoms and normal coronary arteries. Open Hear 2014; 1: e000093.

28. Logue MB, Thomas AM, Barbee JG, et al. Generalized anxiety disorder patients seek evaluation for cardiological symptoms at the same frequency as patients with panic disorder. J Psychiatr Res; 27: 55-9.

29. Deacon B, Lickel J, Abramowitz JS. Medical utilization across the anxiety disorders. J Anxiety Disord 2008; 22: 344-50.

30. Roy-Byrne P, Craske MG, Sullivan G, et al. Delivery of evidence-based treatment for multiple anxiety disorders in primary care: a randomized controlled trial. JAMA 2010; 303: 1921-8.

31. Lecrubier Y. Widespread underrecognition and undertreatment of anxiety and mood disorders: Results from 3 European studies. J Clin Psychiatry 2007; 68: 36-41.

32. Altamura AC, Buoli M, Albano A, et al. Age at onset and latency to treatment (duration of untreated illness) in patients with mood and anxiety disorders: a naturalistic study. Int Clin Psychopharmacol 2010; 25: 172-9.

33. Andrews G, Issakidis C, Sanderson K, et al. Utilising survey data to inform public policy: comparison of the cost-effectiveness of treatment of ten mental disorders. Br J Psychiatry 2004; 184: 526-33.

34 . Olsson I, Mykletun A, Dahl AA. The hospital anxiety and depression rating scale: A crosssectional study of psychometrics and case finding abilities in general practice. BMC Psychiatry $2005 ; 5: 46$.

35. Terluin B, Oosterbaan DB, Brouwers EPM, et al. To what extent does the anxiety scale of the Four-Dimensional Symptom Questionnaire (4DSQ) detect specific types of anxiety disorder in primary care? A psychometric study. BMC Psychiatry 2014; 14: 121. 
36. Guideline Working Group for the Treatment of Patients with Anxiety Disorders in Primary Care. Clinical Practice Guideline for Treatment of Patients with Anxiety Disorders in Primary Care. Full version [Internet]. Madrid: National Plan for the NHS of the MSC. Health technology Assessment Unit. Laín Entralgo Agency. Community of Madrid; 2008. Clinical Practice Guidelines in the NHS. UETS N²006/10. Available at:

http://www.guiasalud.es/GPC/GPC_430_Anxiety_Lain_Entr_compl_en.pdf

37. Whiting PF, Rutjes AWS, Westwood ME, et al. QUADAS-2: a revised tool for the quality assessment of diagnostic accuracy studies. Ann Intern Med 2011; 155: 529-36.

38. Ochodo EA, van Enst WA, Naaktgeboren CA, et al. Incorporating quality assessments of primary studies in the conclusions of diagnostic accuracy reviews: a cross-sectional study. BMC Med Res Methodol 2014; 14: 33.

39. Macaskill P, Gatsonis C, Deeks JJ,et al. Chapter 10: Analysing and Presenting Results. In: Deeks JJ, Bossuyt PM, Gatsonis C, editors. Cochrane Handbook for Systematic Reviews of Diagnostic Test Accuracy; Version 1.0. The Cochrane Collaboration, 2010. Available at: http://srdta.cochrane.org/.

40 . Reitsma JB, Glas AS, Rutjes AWS, et al. Bivariate analysis of sensitivity and specificity produces informative summary measures in diagnostic reviews. J Clin Epidemiol 2005; 58: 982-90.

41. Walter SD. Properties of the summary receiver operating characteristic (SROC) curve for diagnostic test data. Stat Med 2002; 21: 1237-56.

42. Avasthi A, Varma SC, Kulhara P, et al. Diagnosis of common mental disorders by using PRIMEMD Patient Health Questionnaire. Indian J Med Res 2008; 127: 159-64.

43. Balestrieri M, Baldacci S, Bellomo A, et al. Clinical vs. structured interview on anxiety and affective disorders by primary care physicians. Understanding diagnostic discordance. Epidemiol Psichiatr Soc 2007; 16: 144-51.

44 . Baca E, Saiz J, Aguera L, et al. Validacion de la version espanola del PRIME-MD: Un procedimiento para el diagnostico de trastornos mentales en atencinn primaria. Actas Esp Psiquiatr 1999; 27: 375-83.

45. Olafsdottir M, Marcusson J, Skoog I. Mental disorders among elderly people in primary care: The Linkoping study. Acta Psychiatr Scand 2001; 104: 12-8.

46. Al-Shammari SA, Khoja TA, Al-Sabaie A. Anxiety and depression among primary care patients in Riyadh. Int J Ment Health 1993; 22: 53-64.

47 . Azevedo-Marques JM, Zuardi AW. Validity and applicability of the mini international neuropsychiatric interview administered by family resident physicians in primary health care in Brazil. Eur Psychiatry 2009; 24: S888.

48 . El-Farouk El-Rufaie O, Daradkeh TK. Detection of anxiety and depression in primary health care: Assessment by primary health care physician versus assessment by psychiatrist. Prim Care Psychiatry 1996; 2: 189-93. 
49. Norton J, de Roquefeuil G, David M, et al. Prevalence des troubles psychiatriques en medecine generale selon le patient health questionnaire : adequation avec la detection par le medecin et le traitement prescrit. Encephale 2009; 35: 560-9.

50 . Janssen EHC, Van de V, Terluin B, et al. Recognition of anxiety disorders by family physicians after rigorous medical record case extraction. Results of the Netherlands Study of Depression and Anxiety. Gen Hosp Psychiatry 2012; 34: 460-7.

51. Sorsdahl K, Vythilingum B, Stein DJ. A screening tool for social anxiety disorder in primary care: data from South Africa. J NervMent Dis 2012; 200: 163-6.

52. Puddifoot S, Arroll B, Goodyear-Smith F, et al. A new case-finding tool for anxiety: A pragmatic diagnostic validity study in primary care. Int J Psychiatry Med 2007; 37: 371-81.

53. Christensen KS, Toft T, Frostholm L, et al. The FIP Study: A randomised, controlled trial of screening and recognition of psychiatric disorders. Br J Gen Pract 2003; 53: 758-63.

54. Martinez BR, Baylin LA, Ortiz Jimenez MF. Can we detect mental disorders in primary care? Usefulness and agreement of 2 diagnostic instruments. Aten Primaria 1999; 23: 285-8.

55. McGrady A, Lynch DJ, Nagel RW, et al. Coherence between physician diagnosis and patient self reports of anxiety and depression in primary care. J NervMent Dis 2010; 198: 420-4.

56. Lowe B, Grafe K, Zipfel S, et al. Detecting panic disorder in medical and psychosomatic outpatients: comparative validation of the Hospital Anxiety and Depression Scale, the Patient Health Questionnaire, a screening question, and physicians' diagnosis. J Psychosom Res 2003; 55: 515-9.

57. Kirmayer LJ, Robbins JM, Dworkind M, et al. Somatization and the recognition of depression and anxiety in primary care. Am J Psychiatry 1993; 150: 734-41.

58 . Berger P, Sibitz I, Freidl M, et al. P02-271 - The reliability of a brief diagnostic interview, the trips, for the assessment of psychiatric disorders according to ICD-10 in primary care and nonpsychiatric medical settings. Eur Psychiatry 2011; 26, Supple: 867.

59. Borus JF, Howes MJ, Devins NP, et al. Primary health care providers' recognition and diagnosis of mental disorders in their patients. Gen HospPsychiatry 1988; 10: 317-21.

60. National Institute for Health and Care Excellence (2014). Anxiety disorders qs 53. London: National Institute for Health and Care Excellence. Available at: http://www.nice.org.uk/Guidance/qs53.

61. Mitchell AJ, Vaze A, Rao S. Clinical diagnosis of depression in primary care: a meta-analysis. Lancet 2009; 374: 609-19.

62. Mitchell AJ, Meader N, Bird V, et al. Clinical recognition and recording of alcohol disorders by clinicians in primary and secondary care: meta-analysis. Br J Psychiatry 2012; 201: 93-100. 
63. Sinnema H, Franx G, Volker D, et al. Randomised controlled trial of tailored interventions to improve the management of anxiety and depressive disorders in primary care. Implement Sci 2011; 6: 75 .

64. Roy-Byrne P, Veitengruber JP, Bystritsky A, et al. Brief intervention for anxiety in primary care patients. J Am Board Fam Med 2009; 22: 175-86.

65. Pignone MP, Gaynes BN, Rushton JL, et al. Screening for depression in adults: a summary of the evidence for the U.S. Preventive Services Task Force. Ann Intern Med 2002; 136: 765-76.

66. National Institute for Health and Care Excellence (2004). Depression: management of depression in primary and secondary care. Clinical Guideline 23. London: National Institute for Health and Care Excellence. Available at: http://www.nice.org.uk/guidance/cg23.

67. Bunevicius A, Peceliuniene J, Mickuviene N, et al. Screening for depression and anxiety disorders in primary care patients. Depress Anxiety 2007; 24: 455-60.

68. Terluin B, Brouwers EPM, van Marwijk HWJ, et al. Detecting depressive and anxiety disorders in distressed patients in primary care; comparative diagnostic accuracy of the Four-Dimensional Symptom Questionnaire (4DSQ) and the Hospital Anxiety and Depression Scale (HADS). BMC Fam Pract 2009; 10: 58.

69. Davidson JRT, Feltner DE, Dugar A. Management of generalized anxiety disorder in primary care: identifying the challenges and unmet needs. Prim Care Companion J Clin Psychiatry 2010; 12.

70 . Baldwin DS, Anderson IM, Nutt DJ, et al. Evidence-based pharmacological treatment of anxiety disorders, post-traumatic stress disorder and obsessive-compulsive disorder: a revision of the 2005 guidelines from the British Association for Psychopharmacology. J Psychopharmacol 2014; 28 : 403-39.

71. Muntingh ADT, De Heer EW, Van Marwijk HWJ, et al. Screening high-risk patients and assisting in diagnosing anxiety in primary care: the Patient Health Questionnaire evaluated. BMC Psychiatry 2013; 13: 192.

72. Hassink-Franke L, Terluin B, Van Heest F, et al. The NHG guideline Anxiety (second revision of the NHG guideline Anxiety disorders). Huisarts Wet 2012; 55: 68-77.

73. Mathias SD, Fifer SK, Mazonson PD, et al. Necessary but not sufficient: the effect of screening and feedback on outcomes of primary care patients with untreated anxiety. J Gen Intern Med 1994; 9: $606-15$.

74. Katon W, Unützer J. Collaborative care models for depression: time to move from evidence to practice. Arch Intern Med 2006; 166: 2304-6.

75. Gilbody S, Bower P, Fletcher J, et al. Collaborative care for depression: a cumulative metaanalysis and review of longer-term outcomes. Arch Intern Med 2006; 166: 2314-21. 
76. Jorm AF, Kelly CM, Wright A, et al. Belief in dealing with depression alone: results from community surveys of adolescents and adults. J Affect Disord 2006; 96: 59-65.

77. Jorm AF, Christensen H, Griffiths KM. Belief in the harmfulness of antidepressants: results from a national survey of the Australian public. J Affect Disord 2005; 88: 47-53.

78 . Kirmayer LJ, Groleau D, Looper KJ, et al. Explaining medically unexplained symptoms. Can J Psychiatry 2004; 49: 663-72.

79. Wittchen HU, Lieb R, Wunderlich U, et al. Comorbidity in primary care: presentation and consequences. J Clin Psychiatry 1999; 60 Suppl 7: 29-36; discussion 37-8.

80. O'Connor DW, Rosewarne R, Bruce A. Depression in primary care. 1: elderly patients' disclosure of depressive symptoms to their doctors. Int Psychogeriatr 2001; 13: 359-65.

81. Kessler D, Lloyd K, Lewis G, et al. Cross sectional study of symptom attribution and recognition of depression and anxiety in primary care. BMJ 1999; 318: 436-9.

82. Ansseau M, Dierick M, Buntinkx F, et al. High prevalence of mental disorders in primary care. J Affect Disord 2004; 78: 49-55.

83. Robbins JM, Kirmayer LJ, Cathébras P, et al. Physician characteristics and the recognition of depression and anxiety in primary care. Med Care 1994; 32: 795-812.

84. Van Rijswijk E, van Hout H, van de Lisdonk E, et al. Barriers in recognising, diagnosing and managing depressive and anxiety disorders as experienced by Family Physicians; a focus group study. BMC Fam Pract 2009; 10: 52.

85. Stone L. Making sense of medically unexplained symptoms in general practice: a grounded theory study. Ment Health Fam Med 2013; 10: 101-11.

86. Upton MW, Evans M, Goldberg DP, et al. Evaluation of ICD-10 PHC mental health guidelines in detecting and managing depression within primary care. Br J Psychiatry 1999; 175: 476-82.

87. Croudance T, Evans J, Harrison G, et al. Impact of the ICD-10 Primary Health Care (PHC) diagnostic and management guidelines for mental disorders on detection and outcome in primary care: Cluster randomised controlled trial. Br J Psychiatry 2003; 182: 20-30.

88. McCall L, Clarke DM, Rowley G. A questionnaire to measure general practitioners' attitudes to their role in the management of patients with depression and anxiety. Aust Fam Physician 2002; 31: 299-303.

89. Reilly S, Planner C, Hann M, et al. The role of primary care in service provision for people with severe mental illness in the United Kingdom. PLoS One 2012; 7: e36468.

90 . Kessler D, Bennewith O, Lewis G, et al. Detection of depression and anxiety in primary care: follow up study. BMJ 2002; 325: 1016-7. 
91. Slone L. Prevalence of PTSD in Primary Care settings. PTSD Res Q 2006; 17: 1-8.

92. Thulesius H, Alveblom A-K, Håkansson A. Post-traumatic stress associated with low self-rated well-being in primary care attenders. Nord J Psychiatry 2004; 58: 261-6.

93. Pereda N, Forero CG. Contribution of Criterion A2 to PTSD Screening in the Presence of Traumatic Events. J Trauma Stress 2012; 25: 587-91.

94. Hirschfeld RMA. The Comorbidity of Major Depression and Anxiety Disorders: Recognition and Management in Primary Care. Prim Care Companion J Clin Psychiatry 2001; 3: 244-54.

95. Bryant C. Anxiety and depression in old age: challenges in recognition and diagnosis. Int Psychogeriatr 2010; 22: 511-3.

96. Fuentes K, Cox BJ. Prevalence of anxiety disorders in elderly adults: a critical analysis. J Behav Ther Exp Psychiatry 1997; 28: 269-79.

97. Beesdo K, Knappe S, Pine DS. Anxiety and anxiety disorders in children and adolescents: developmental issues and implications for DSM-V. Psychiatr Clin North Am 2009; 32: 483-524.

98. Whiting P, Rutjes AWS, Reitsma JB, et al. Sources of variation and bias in studies of diagnostic accuracy: a systematic review. Ann Intern Med 2004; 140: 189-202.

99 . Chopra SS. MSJAMA: Industry funding of clinical trials: benefit or bias? JAMA 2003; 290: 1134.

100. Weissman MM, Olfson M, Leon AC, et al. Brief diagnostic interviews (SDDS-PC) for multiple mental disorders in primary care. A pilot study. Arch Fam Med 1995; 4: 220-7.

101. National Institute for Health and Care Excellence (2011). Common Mental Health Disorders: Identification and Pathways to care. London: National Institute for Health and Care Excellence. Available at: http://www.nice.org.uk/guidance/cg123/resources/guidance-common-mental-healthdisorders-pdf.

102. Christensen KS, Fink P, Toft T, et al. A brief case-finding questionnaire for common mental disorders: the CMDQ. Fam Pract 2005; 22: 448-57.

103. Hoyer J, Wittchen HU. Generalized anxiety disorders in primary medical care. Versicherungsmedizin 2003; 55: 127-35.

104 . Hoyer I, Krause P, Hofler M, et al. When and how well does the family physician recognize generalized anxiety disorders and depressions? Fortschr Med Orig; Wann und wie gut erkennt der Hausarzt Gen Angststorungen und Depress 2001; 119 Suppl : 26-35.

105. Ostby-Deglum I, Mykletun A, Dahl AA. The Hospital Anxiety and Depression Rating Scale (HADS) as a case finder for anxiety disorder and depression in Norwegian general practices. In Acta psychiatrica ScandinavicaSupplementum 421.: 43-4. Blackwell Munksgaard, 35 Norre Sogade, PO BOX 2148, DK-1016 Copenhagen, Denmark, 2004. 
106. Olfson M, Leon AC, Broadhead WE, et al. The SDDS-PC: A diagnostic aid for multiple mental disorders in primary care. Psychopharmacol Bull 1995; 31: 415-20. 
Tables

Table 1 - Study characteristics of included articles

\begin{tabular}{|c|c|c|c|c|c|c|c|c|c|c|c|}
\hline Author & Country & Language & $\begin{array}{l}\text { Number of } \\
\text { particpating } \\
\text { GPs }^{1}\end{array}$ & $\begin{array}{c}\text { N (\% } \\
\text { women } \\
)\end{array}$ & $\begin{array}{c}\text { Mean } \\
\text { patient } \\
\text { age } \\
\text { (years) }\end{array}$ & $\begin{array}{l}\text { Case- } \\
\text { ascertainment }\end{array}$ & $\begin{array}{c}\text { Patient } \\
\text { complaint }^{2}\end{array}$ & $\begin{array}{c}\text { Method of } \\
\text { diagnosis }^{3} \\
\text { (Type of } \\
\text { instrument) }\end{array}$ & Diagnosis $^{4}$ & $\begin{array}{c}\text { Gold } \\
\text { standard }\end{array}$ & $\begin{array}{c}\text { Diagnostic } \\
\text { criteria }\end{array}$ \\
\hline $\begin{array}{l}\text { Ajit Avasthi } \\
\text { et al } 2006 \\
{[42]}\end{array}$ & India & English & NI & $\begin{array}{c}500 \\
(44.6 \%)\end{array}$ & 38.7 & $\begin{array}{l}\text { Routine clinical } \\
\text { interview }\end{array}$ & PhysC & Unassisted & $\begin{array}{l}\text { Anxiety } \\
\text { disorder }\end{array}$ & $\begin{array}{l}\text { PRIME- } \\
\text { MD PHQ }^{5}\end{array}$ & DSM-IV \\
\hline
\end{tabular}

\begin{tabular}{|c|c|c|c|c|c|c|c|c|c|c|c|}
\hline $\begin{array}{l}\text { Al- } \\
\text { Shammari } \\
\text { et al } 1993 \\
{[46]}\end{array}$ & Saudi Arabia & English & NI & $\begin{array}{c}411 \\
(70.3 \%)\end{array}$ & 28.7 & $\begin{array}{l}\text { GP rating form } \\
\text { based on clinical } \\
\text { interview }\end{array}$ & NI & Unassisted & $\begin{array}{l}\text { Anxiety } \\
\text { disorder }\end{array}$ & HADS & \\
\hline $\begin{array}{l}\text { Azevedo } \\
\text { Marques et } \\
\text { al } 2008^{[47]}\end{array}$ & Brazil & English & 25 & $\begin{array}{c}120 \\
(51.7 \%)\end{array}$ & NI & $\begin{array}{l}\text { Structured } \\
\text { phyisican } \\
\text { interview with } \\
\text { MINI }\end{array}$ & NI & $\begin{array}{l}\text { Assisted } \\
\text { (MINI) }\end{array}$ & $\begin{array}{l}\text { Anxiety } \\
\text { disorder }\end{array}$ & SCID & DSM-IV \\
\hline $\begin{array}{l}\text { Baca et al } \\
1999^{[44]}\end{array}$ & Spain & Spanish & NI & $\begin{array}{c}395 \\
(60.8 \%)\end{array}$ & 50.7 & $\begin{array}{l}\text { Structured } \\
\text { phyisican } \\
\text { interview with } \\
\text { PRIME-MD }\end{array}$ & NI & $\begin{array}{l}\text { Assisted } \\
\text { (PRIME- } \\
\text { MD) }\end{array}$ & $\begin{array}{l}\text { Anxiety } \\
\text { disorder }\end{array}$ & SCAN & DSM-IV \\
\hline $\begin{array}{l}\text { Balestrieri } \\
\text { et al } 2007 \\
{[43]}\end{array}$ & Italy & English & 143 & $\begin{array}{c}897 \\
(55.5 \%)\end{array}$ & 42 & $\begin{array}{l}\text { Routine clinical } \\
\text { interview }\end{array}$ & NI & Unassisted & $\begin{array}{l}\text { Anxiety } \\
\text { disorder }\end{array}$ & $\mathrm{MINI}^{6}$ & DSM-IV \\
\hline $\begin{array}{l}\text { Berger et al } \\
2011^{[58]}\end{array}$ & Austria & English & NI & $\begin{array}{l}290 \\
(\mathrm{NI})\end{array}$ & NI & $\begin{array}{l}\text { Physician } \\
\text { Interview with the } \\
\text { TRIPS (diagnostic } \\
\text { interview) }\end{array}$ & NI & $\begin{array}{l}\text { Assisted } \\
\text { (TRIPS) }\end{array}$ & $\begin{array}{l}\text { Anxiety } \\
\text { disorder }\end{array}$ & CIDI & ICD-10 \\
\hline $\begin{array}{l}\text { Borus et al } \\
1988^{[59]}\end{array}$ & US & English & 2 & 88 (NI) & NI & $\begin{array}{l}\text { GPs completed a } \\
\text { Primary Provider } \\
\text { Rating Scale }\end{array}$ & NI & Unassisted & $\begin{array}{l}\text { Anxiety } \\
\text { disorder }\end{array}$ & SCID & DSM-III \\
\hline
\end{tabular}


Carlos G. Forero

\begin{tabular}{|c|c|c|c|c|c|c|c|c|c|c|c|}
\hline $\begin{array}{l}\text { DASMAP } \\
\text { study: } \\
\text { Fernandez } \\
\text { et al } 2012 \\
{[16]}\end{array}$ & Spain & English & 618 & $\begin{array}{l}3815 \\
(63 \%)\end{array}$ & 54.3 & $\begin{array}{l}\text { Recognition from } \\
\text { medical records } \\
\text { over the previous } \\
12 \text { months }\end{array}$ & $\begin{array}{l}\text { PhysC, MC, } \\
\text { Adm }\end{array}$ & Unassisted & $\begin{array}{l}\text { Anxiety } \\
\text { disorder }\end{array}$ & SCID-I & DSM-IV \\
\hline $\begin{array}{l}\text { FIP study } \\
\text { (blinding } \\
\text { group): } \\
\text { Christensen } \\
\text { et al } 2003 \\
\text { [53]; } \\
\text { Christensen } \\
\text { et al } 2005 \\
\text { [102] }\end{array}$ & Norway & English & 38 & $\begin{array}{l}885 \\
(61 \%)\end{array}$ & 38.2 & $\begin{array}{l}\text { Routine clinical } \\
\text { interview }\end{array}$ & $\begin{array}{l}\text { New health } \\
\text { problem }\end{array}$ & Unassisted & $\begin{array}{l}\text { Anxiety } \\
\text { disorder }\end{array}$ & SCAN & ICD-10 \\
\hline $\begin{array}{l}\text { FIP study } \\
\text { (disclosure } \\
\text { of } \\
\text { screening } \\
\text { information } \\
\text { ): } \\
\text { Christensen } \\
\text { et al } 2003 \\
{[53] \text {; }} \\
\text { Christensen } \\
\text { et al } 2005 \\
{[102]}\end{array}$ & Norway & English & 38 & $\begin{array}{l}900 \\
(59 \%)\end{array}$ & 39.3 & $\begin{array}{l}\text { Physician } \\
\text { interview guided } \\
\text { by a self-reported } \\
\text { screening } \\
\text { questionnaire }\end{array}$ & $\begin{array}{l}\text { New health } \\
\text { problem }\end{array}$ & $\begin{array}{l}\text { Assisted } \\
\text { (CMDQ) }\end{array}$ & $\begin{array}{l}\text { Anxiety } \\
\text { disorder }\end{array}$ & SCAN & ICD-10 \\
\hline $\begin{array}{l}\text { GAD-P } \\
\text { study: } \\
\text { Wittchen et } \\
\text { al } 2002^{[18]} \text {; } \\
\text { Hoyer et al } \\
2003^{[103]} \text {; } \\
\text { Hoyer et al } \\
2001^{[104]} \text {; }\end{array}$ & Germany & $\begin{array}{c}\text { English/ } \\
\text { German / } \\
\text { German }\end{array}$ & 558 & $\begin{array}{c}17739 \\
(58.9 \%)\end{array}$ & 50.3 & $\begin{array}{l}\text { GP completed a } \\
\text { questionnaire } \\
\text { (standardized } \\
\text { assessment form } \\
\text { using the Clinical } \\
\text { Global } \\
\text { Impressions scale } \\
\text { score) for each } \\
\text { patient at the end } \\
\text { of the visit }\end{array}$ & MC, PhysC & $\begin{array}{l}\text { Assisted } \\
\text { (CGI-S) }\end{array}$ & GAD & GAS-Q & $\begin{array}{l}\text { DSM-IV \& } \\
\text { ICD-10 }\end{array}$ \\
\hline
\end{tabular}


Carlos G. Forero

\begin{tabular}{|c|c|c|c|c|c|c|c|c|c|c|c|}
\hline $\begin{array}{l}\text { Kirmayer } \\
\text { et al } 1993 \\
\text { [57] }\end{array}$ & Canada & English & NI & $\begin{array}{c}685 \\
(58 \%)\end{array}$ & 44.4 & $\begin{array}{l}\text { Recognition from } \\
\text { medical records } \\
\text { over the } 12 \text { months } \\
\text { following the } \\
\text { initial study visit }\end{array}$ & $\begin{array}{l}\text { New health } \\
\text { problem }\end{array}$ & NI & $\begin{array}{l}\text { Anxiety } \\
\text { disorder }\end{array}$ & DIS-III & DSM-III \\
\hline $\begin{array}{l}\text { Linkoping } \\
\text { Study } \\
\text { Olafsdottir } \\
\text { et al } 2001 \\
{[45]}\end{array}$ & Sweden & English & 11 & $\begin{array}{c}350 \\
(59.1 \%)\end{array}$ & 78.6 & $\begin{array}{l}\text { Recognition from } \\
\text { medical records }\end{array}$ & PhysC, MC & Unassisted & $\begin{array}{l}\text { Anxiety } \\
\text { disorder }\end{array}$ & $\begin{array}{l}\text { Psychiatric } \\
\text { interview }^{8}\end{array}$ & DSM-III-R \\
\hline $\begin{array}{l}\text { Lowe et al } \\
2002^{[56]}\end{array}$ & Germany & English & NI & $\begin{array}{c}499 \\
(66.7 \%)\end{array}$ & 41.8 & $\begin{array}{l}\text { GPs completed a } \\
\text { short questionnaire } \\
\text { after the } \\
\text { consultation }\end{array}$ & NI & Unassisted & $\begin{array}{l}\text { Panic } \\
\text { disorder }\end{array}$ & SCID & DSM-IV \\
\hline $\begin{array}{l}\text { Martinez } \\
\text { Bernardos } \\
\text { et al } 1999 \\
{[54]}\end{array}$ & Spain & Spanish & NI & $\begin{array}{c}175 \\
(56.6 \%)\end{array}$ & NI & $\begin{array}{l}\text { Structured } \\
\text { physician } \\
\text { interview with } \\
\text { PRIME-MD }\end{array}$ & NI & $\begin{array}{l}\text { Assisted } \\
\text { (PRIME- } \\
\text { MD) }\end{array}$ & $\begin{array}{l}\text { Anxiety } \\
\text { disorder }\end{array}$ & GAS & \\
\hline $\begin{array}{l}\text { McGrady } \\
\text { et al } 2010 \\
{[55]}\end{array}$ & NI & English & 15 & $\begin{array}{c}165 \\
(66.7 \%)\end{array}$ & 52.9 & $\begin{array}{l}\text { Recognition from } \\
\text { medical records }\end{array}$ & NI & Unassisted & $\begin{array}{l}\text { Anxiety } \\
\text { disorder }\end{array}$ & $\begin{array}{l}\text { PRIME- } \\
\text { MD (self- } \\
\text { reported) }\end{array}$ & DSM-IV \\
\hline $\begin{array}{l}\text { NESDA } \\
\text { study: } \\
\text { Janssen et } \\
\text { al } 2012^{[50]}\end{array}$ & $\begin{array}{l}\text { The } \\
\text { Netherlands }\end{array}$ & English & 33 & $\begin{array}{c}816 \\
(68 \%)\end{array}$ & 46.2 & $\begin{array}{l}\text { Recognition from } \\
\text { medical records } \\
\text { starting from } 1 \\
\text { year prior to } \\
\text { inclusion in } \\
\text { NESDA study to } 1 \\
\text { year after } \\
\text { inclusion }\end{array}$ & NI & Unassisted & $\begin{array}{l}\text { Anxiety } \\
\text { disorder }\end{array}$ & CIDI v 2.1 & DSM-IV \\
\hline $\begin{array}{l}\text { Norton et al } \\
2009^{[49]}\end{array}$ & France & French & 46 & $\begin{array}{c}1151 \\
(61.5 \%)\end{array}$ & 44.5 & $\begin{array}{l}\text { GP encounter form } \\
\text { based on clinical } \\
\text { interview }\end{array}$ & NI & Unassisted & $\begin{array}{l}\text { Anxiety } \\
\text { disorder }\end{array}$ & PHQ & DSM-IV \\
\hline
\end{tabular}


Carlos G. Forero

\begin{tabular}{|c|c|c|c|c|c|c|c|c|c|c|c|}
\hline $\begin{array}{l}\text { Norway } \\
\text { study: } \\
\text { Olsson et al } \\
2005^{[34]} \text {; } \\
\text { Ostby- } \\
\text { Deglum et } \\
\text { al } 2004^{[105]}\end{array}$ & Norway & English & 136 & $\begin{array}{c}1238 \\
(63.2 \%)\end{array}$ & 46.9 & $\begin{array}{l}\text { Physician } \\
\text { Interview with the } \\
\text { Clinical Global } \\
\text { Index Severity } \\
\text { Scale (CGI-S) }\end{array}$ & NI & $\begin{array}{l}\text { Assisted } \\
\text { (CGI-S) }\end{array}$ & GAD & GAS-Q & $\begin{array}{l}\text { DSM-IV; } \\
\text { ICD-10 }\end{array}$ \\
\hline $\begin{array}{l}\text { Olfson et al } \\
1995^{[106]} ; \\
\text { Weissman } \\
\text { et al } 1995 \\
{\left[{ }^{100]}\right.}\end{array}$ & US & English & 16 & $97(\mathrm{NI})$ & NI & $\begin{array}{l}\text { Physician } \\
\text { Interview with the } \\
\text { SDDS-PC } \\
\text { (diagnostic } \\
\text { modules) }\end{array}$ & NI & $\begin{array}{l}\text { Assisted } \\
\text { (SDDS-PC) }\end{array}$ & GAD & SCID-P & DSM-III-R \\
\hline $\begin{array}{l}\text { Puddifoot } \\
\text { et al } 2012 \\
\text { [52] }\end{array}$ & New Zealand & English & 19 & $\begin{array}{c}982 \\
(72.3 \%)\end{array}$ & 46.5 & $\begin{array}{l}\text { Physician } \\
\text { interview with a } \\
\text { case-finding } \\
\text { question and a } \\
\text { help question }\end{array}$ & NI & $\begin{array}{l}\text { Assisted } \\
\text { (Case finding } \\
\text { questions) }\end{array}$ & $\begin{array}{l}\text { Anxiety } \\
\text { disorder }\end{array}$ & HADS & \\
\hline $\begin{array}{l}\text { Sorsdahl et } \\
\text { al } 2012^{[51]}\end{array}$ & South Africa & English & NI & $\begin{array}{c}177 \\
(59.9 \%)\end{array}$ & 38 & $\begin{array}{l}\text { Physician } \\
\text { Interview with the } \\
\text { SAS-Q }\end{array}$ & NI & $\begin{array}{l}\text { Assisted } \\
\text { (SAS-Q) }\end{array}$ & SAD & MINI & DSM-IV \\
\hline $\begin{array}{l}\text { Spitzer et al } \\
1994^{[20]}\end{array}$ & US & English & 31 & $\begin{array}{l}431 \\
\text { (NI) }\end{array}$ & NI & $\begin{array}{l}\text { Structured } \\
\text { phyisican } \\
\text { interview with } \\
\text { PRIME-MD }\end{array}$ & NI & $\begin{array}{l}\text { Assisted } \\
\text { (PRIME- } \\
\text { MD) }\end{array}$ & $\begin{array}{l}\text { Anxiety } \\
\text { disorder }\end{array}$ & SCID & DSM-III-R \\
\hline $\begin{array}{l}\text { Weiller et } \\
\text { al } 1998^{[22]}\end{array}$ & $\begin{array}{l}\text { Germany; } \\
\text { UK; France; } \\
\text { The }\end{array}$ & English & NI & $\begin{array}{r}1973 \\
(\mathrm{NI})\end{array}$ & NI & $\begin{array}{l}\text { GPs completed an } \\
\text { encounter form for } \\
\text { each patient }\end{array}$ & MC, PhysC & NI & $\begin{array}{l}\text { Anxiety } \\
\text { disorder }\end{array}$ & CIDI & ICD-10 \\
\hline
\end{tabular}

${ }^{1} N I$ : No information

${ }^{2}$ NI: No information; PhysC: Physical Complaints; MC: Mental Complaints; Adm: Administrative reasons

${ }^{3}$ Assisted, where the practitioner tries to diagnose anxiety disorders with the help of any type of questionnaire or scale; Unassisted, where the practitioner tries to make a diagnosis without any help from severity scales or diagnostic instruments

${ }^{4} G A D$ : Generalized Anxiety Disorder; SAD: Social Anxiety Disorder 
${ }^{5}$ PRIME-MD PHQ: self-reported, but the final decision belongs to the treating physician or research worker

${ }^{6} \mathrm{MINI}$, administered by the same GP

${ }^{7}$ Psychiatric Interview: Standardized clinical interview with a psychiatrist

${ }^{8}$ Psychiatric Interview: Conducted by the GP; it included MINI and Comprehensive Psychopathological Rating Scale

CGI-S: Clinical Global Impressions Scale; CIDI: Composite International Diagnostic Interview; CMDQ: Common Mental Disorder Questionnaire; DIS-III: Diagnostic Interview Schedule, Version III; GAS: Goldberg Anxiety Scale; GAS-Q: Generalized Anxiety Screening Questionnaire; HADS: Hospital Anxiety and Depression Scale; MINI: Mini-International Neuropsychiatric Interview; PHQ: The Patient Health Questionnaire; PRIME-MD: Primary Care Evaluation of Mental Disorders; SAS-Q: Social Anxiety Screening Questionnaire; SCID: Structured Clinical Interview for DSM Disorders; SCID-P: Structured Clinical Interview for DSM Disorders - Patient Edition; SCID-I: The Structured Clinical Interview for DSM-IV Axis I Disorders; SCAN: The Schedules for Clinical Assessment in Neuropsychiatry; SDDS-PC: The Symptom Driven Diagnostic System for Primary Care; 
Figure 1 - Flowchart of literature review process of studies on accuracy of assisted and unassisted diagnoses of anxiety disorders by GPs. Rejection reasons for abstract and full-text steps.

Inclusion Criteria no.1 - The study reports on the accuracy of a diagnosis of any anxiety disorder in persons

Inclusion Criteria no. 2 - The diagnosis is made by a general practitioner

Inclusion Criteria no. 3 - The study population includes, at least partially, patients attending Primary Care/Family or General Practices/Community Health Centres/Community outpatient units, etc.

Inclusion Criteria no. 4 - The study provides specific data/results on the Primary Care population

Exclusion Criteria no.1 - The entire study population comes from a general population sample, a specific sample with special characteristics or from health care levels different from Primary Care

Exclusion Criteria no. 2 - The diagnosis is made by a healthcare professional with specific training in mental health.

Exclusion Criteria no. 3 - Patients were selected because of a specific physical pathology or mental disorder different from any anxiety disorder.

Exclusion Criteria no. 4 - The study population was pre-screened or selected because of a previous/suspected diagnosis of anxiety disorders.

Exclusion Criteria no. 5 - The study is a vignette study / case report / case-series report study. 
3424 abstracts identified through database searching

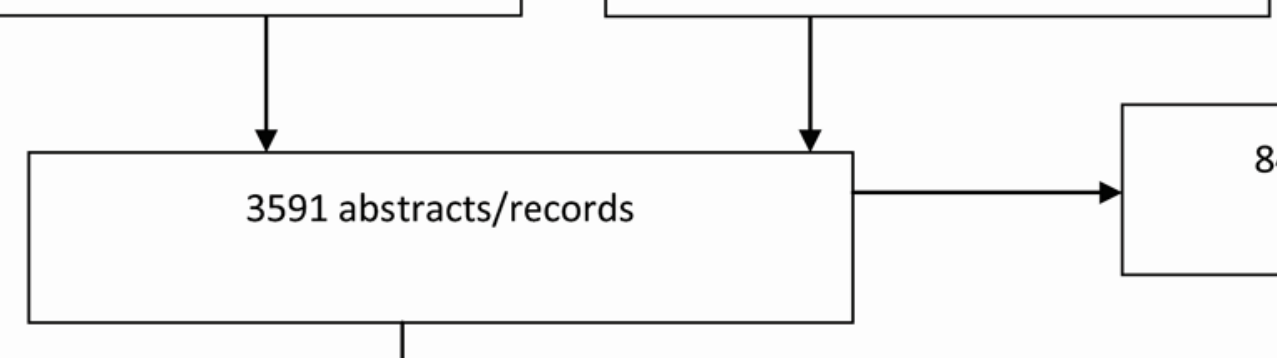

167 additional records identified through other sources

84 duplicates removed

\section{0 abstracts/records excluded}

$81.82 \%$ not meeting Inclusion Criteria no. 1 $5.28 \%$ not meeting Inclusion Criteria no. 2

$2.90 \%$ not meeting Inclusion Criteria no. 3

$0.17 \%$ not meeting Inclusion Criteria no. 4

3.56\% meeting Exclusion Criteria no. 1

$0.10 \%$ meeting Exclusion Criteria no. 2

3.93\% meeting Exclusion Criteria no. 3

$1.78 \%$ meeting Exclusion Criteria no. 4

$0.46 \%$ meeting Exclusion Criteria no. 5

\section{Full-text articles excluded, with reasons}

$80.36 \%$ not meeting Inclusion Criteria no. 1

$8.72 \%$ not meeting Inclusion Criteria no. 2

$2.24 \%$ not meeting Inclusion Criteria no. 3

$0.45 \%$ meeting Exclusion Criteria no. 1

$0.22 \%$ meeting Exclusion Criteria no. 2

$0.45 \%$ meeting Exclusion Criteria no. 3

2.68\% meeting Exclusion Criteria no. 4

$0.45 \%$ meeting Exclusion Criteria no. 5

$2.01 \%$ articles in other languages

$2.46 \%$ articles not found 
Figure 2 - Quality assessment of included studies. QUADAS - 2 results.

FIP study 2000b: FIP study, disclosure of screening information

FIP study 2000a: FIP study, blinding group 

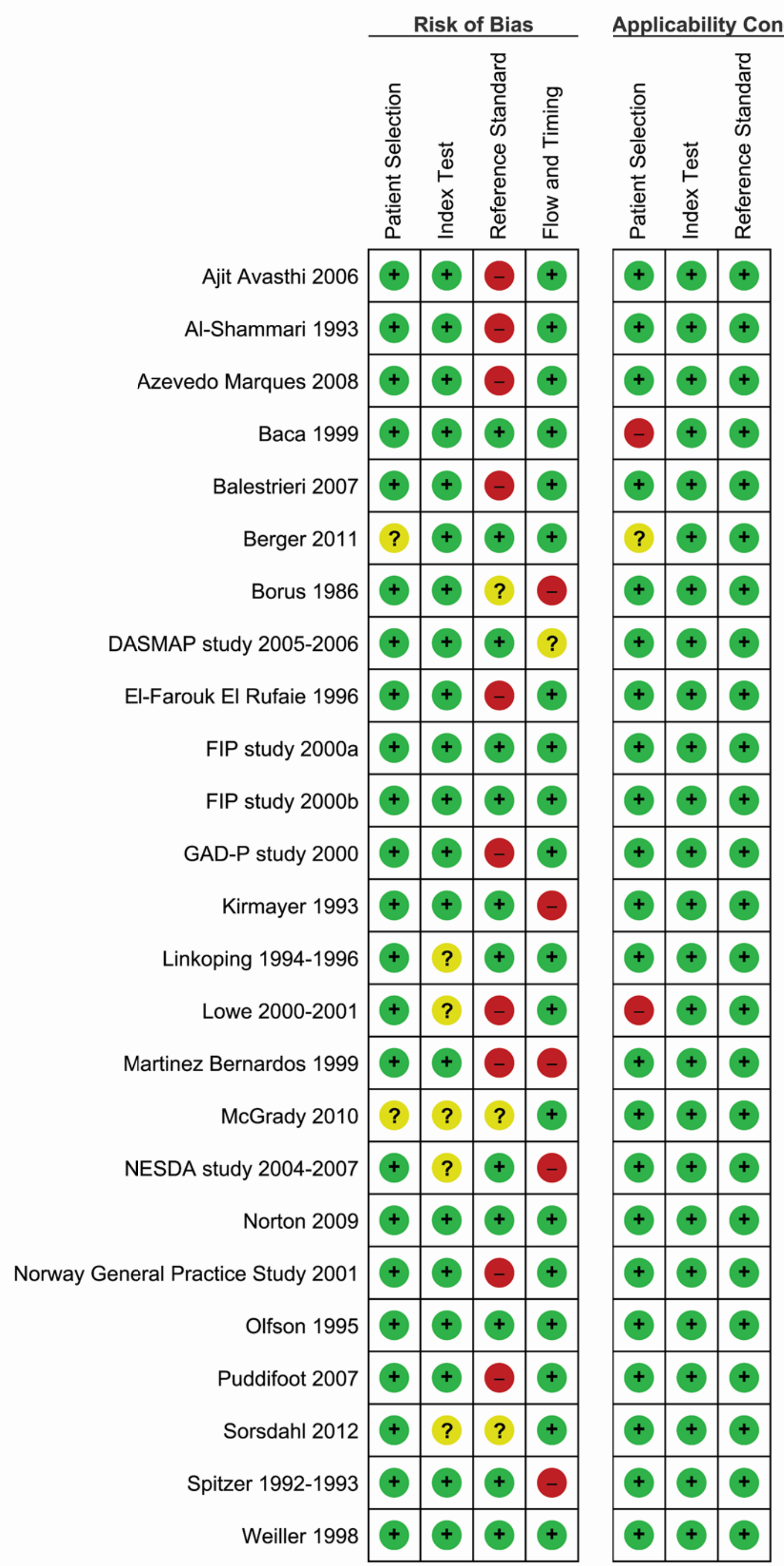
Carlos G. Forero

Figure 3 - Forest plot of included studies by method of diagnosis

TP - True positive; FP - False negative; FN - False negative; TN - True Negative; $95 \%$ CI - $95 \%$ Confidence Interval; Red vertical lines - Pooled estimates of sensitivity/specificity of GPs diagnoses of any anxiety disorder for all included studies 


\section{Study}

GAD-P study 2000

Olfson 1995

FIP study 2000b

Norway General Practice Study 2001

Puddifoot 2007

Martinez Bernardos 1999

Spitzer 1992-1993

Berger 2011

Baca 1999

Sorsdahl 2012

Azevedo Marques 2008

Kirmayer 1993

Weiller 1998

NESDA study 2004-2007

Lowe 2000-2001

Borus 1986

Al-Shammari 1993

McGrady 2010

DASMAP study 2005-2006

FIP study 2000a

Linkoping 1994-1996

Ajit Avasthi 2006

El-Farouk El Rufaie 1996

Norton 2009

Balestrieri 2007

$\begin{array}{rrrr}\text { TP } & \text { FP } & \text { FN } & \text { TN } \\ 349 & 1726 & 595 & 15069 \\ 3 & 17 & 5 & 72 \\ 32 & 39 & 50 & 240 \\ 38 & 179 & 35 & 986 \\ 34 & 120 & 25 & 803 \\ 45 & 4 & 21 & 105 \\ 57 & 35 & 25 & 314 \\ 46 & 27 & 18 & 199 \\ 35 & 32 & 12 & 233 \\ 27 & 54 & 5 & 109 \\ 19 & 5 & 2 & 94 \\ 1 & 7 & 9 & 668 \\ 223 & 122 & 183 & 1445 \\ 28 & 10 & 280 & 498 \\ 2 & 3 & 11 & 276 \\ 3 & 19 & 15 & 51 \\ 12 & 13 & 51 & 335 \\ 18 & 16 & 62 & 63 \\ 124 & 260 & 404 & 2688 \\ 18 & 35 & 55 & 230 \\ 11 & 29 & 26 & 284 \\ 35 & 44 & 73 & 348 \\ 18 & 28 & 13 & 64 \\ 82 & 31 & 41 & 979 \\ 105 & 117 & 40 & 635\end{array}$

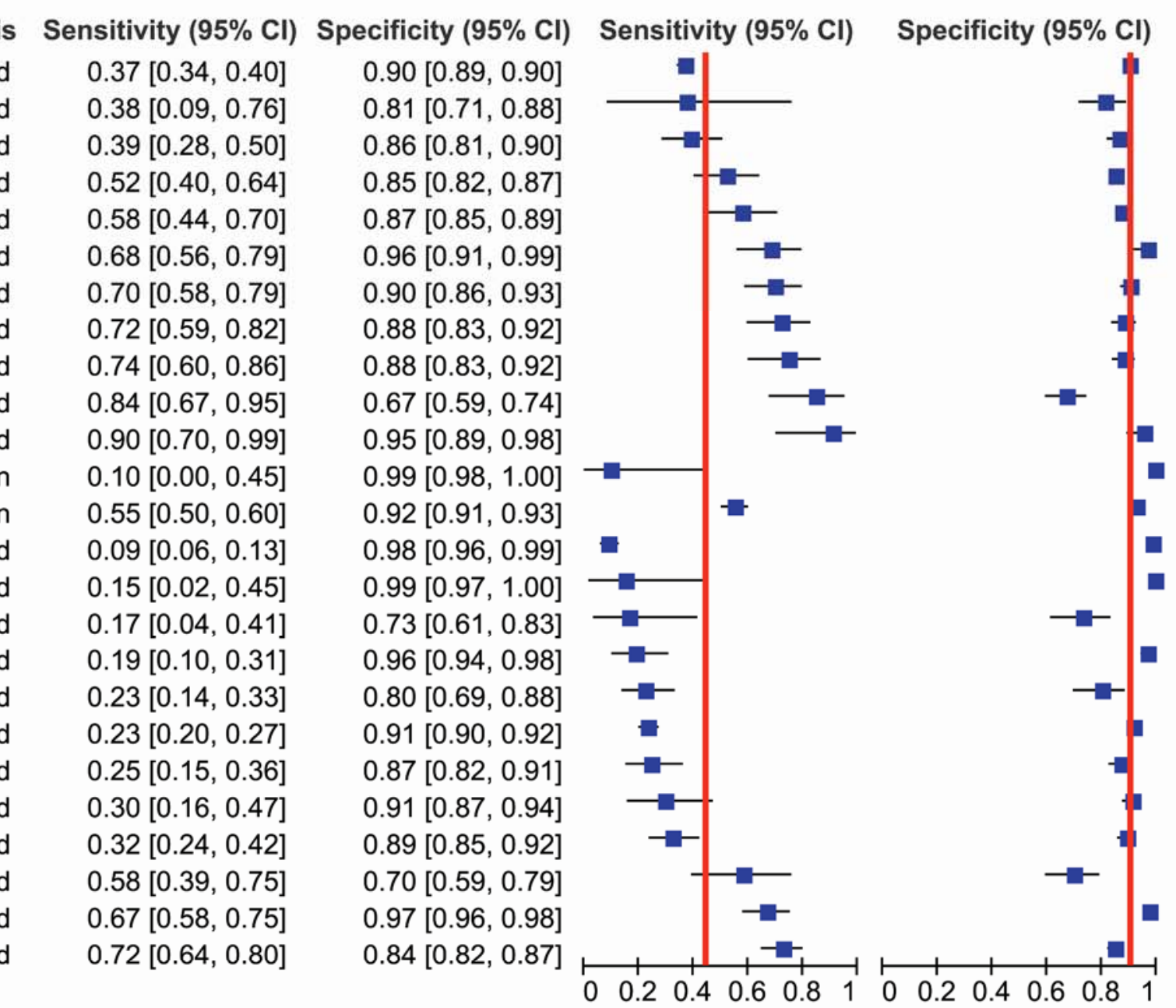


Figure 4.A - Bivariate meta-analysis of anxiety disorders' diagnoses in Primary Care for all included studies and by method of diagnosis

- Summary Point; ------ $95 \%$ prediction region; ..... 95\% confidence interval 
Carlos G. Forero

Figure 4.B - Bivariate meta-analysis of anxiety disorders' diagnoses in Primary Care by method of diagnosis

- Summary Point for unassisted diagnoses, where the practitioner tries to make a diagnosis without any help from severity scales or diagnostic instruments,; ------ $95 \%$ prediction region; ...... 95\% confidence interval

- Summary Point for assisted diagnoses, where the practitioner tries to diagnose anxiety disorders with the help of any type of questionnaire or scale; ------ $95 \%$ prediction region; ...... $95 \%$ confidence interval 

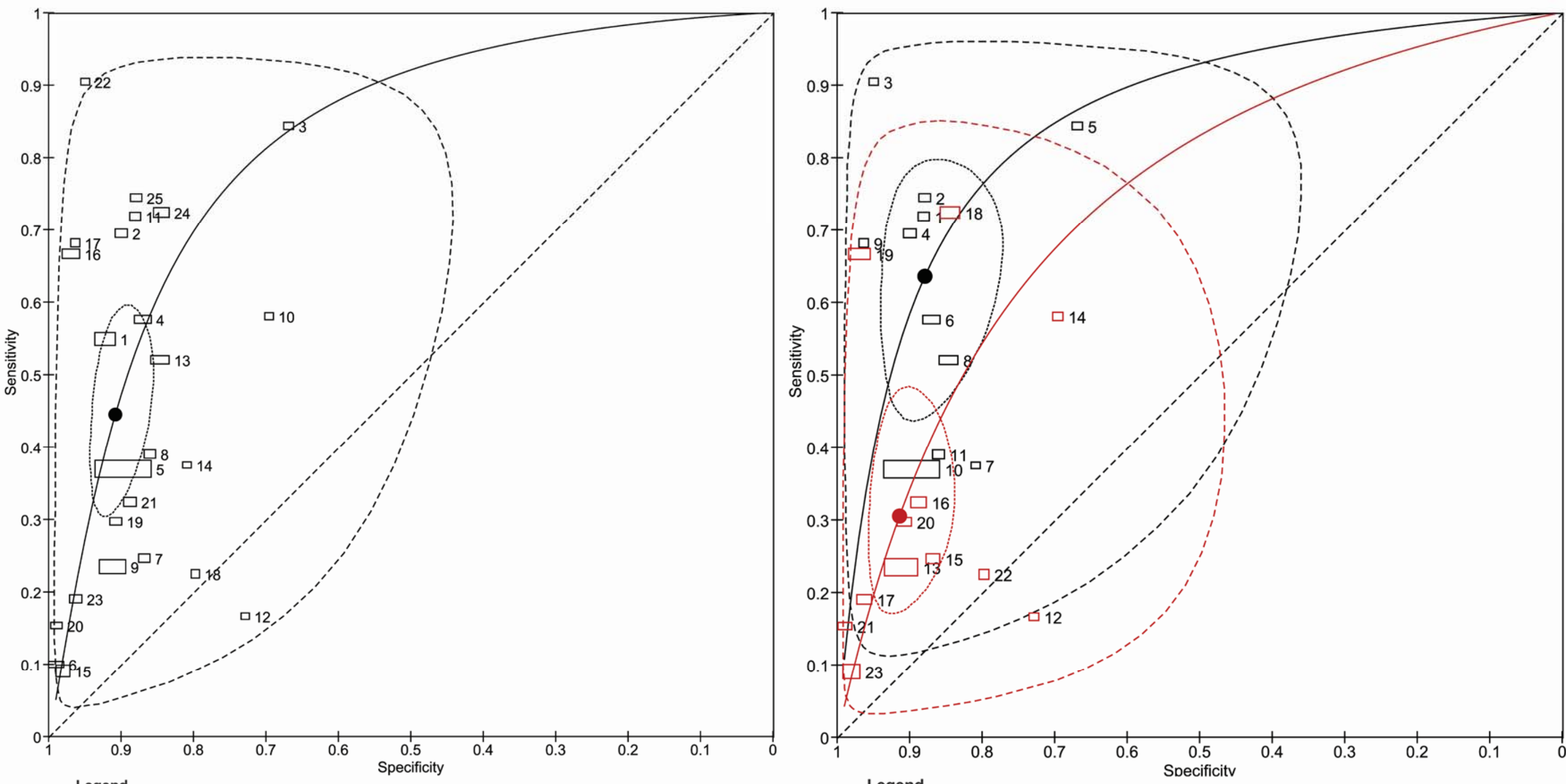

\begin{tabular}{|ll}
\hline & \\
1 Weiller 1998 & 14 Olfson 1995 \\
2 Spitzer 1992-1993 & 15 NESDA study 2004-2007 \\
3 Sorsdahl 2012 & 16 Norton 2009 \\
4 Puddifoot 2007 & 17 Martinez Bernardos 1999 \\
5 GAD-P study 2000 & 18 McGrady 2010 \\
6 Kirmayer 1993 & 19 Linkoping 1994-1996 \\
7 FII study 2000a & 20 Lowe 2000-2001 \\
8 FIP study 2000b & 21 Ajit Avasthi 2006 \\
9 DASMAP study 2005-2006 & 22 Azevedo Marques 2008 \\
10 El-Farouk El Rufaie 1996 & 23 Al-Shammari 1993 \\
11 Berger 2011 & 24 Balestrieri 2007 \\
12 Borus 1986 & 25 Baca 1999 \\
13 Norway General Practice Study 2001 & \\
\hline
\end{tabular}

$\square$ Study estimate - Summary Point $-\cdots 95 \%$ confidence region $--95 \%$ prediction region

\begin{tabular}{|ll}
\hline Assisted & $\square$ Unassisted \\
& \\
1 Berger 2011 & 13 DASMAP study 2005-2006 \\
2 Baca 1999 & 14 El-Farouk El Rufaie 1996 \\
3 Azevedo Marques 2008 & 15 FIP study 2000a \\
4 Spitzer 1992-1993 & 16 Ajit Avasthi 2006 \\
5 Sorsdahl 2012 & 17 Al-Shammari 1993 \\
6 Puddifoot 2007 & 18 Balestrieri 2007 \\
7 Olfson 1995 & 19 Norton 2009 \\
8 Norway General Practice Study 2001 & 20 Linkoping 1994-1996 \\
9 Martinez Bernardos 1999 & 21 Lowe 2000-2001 \\
10 GAD-P study 2000 & 22 McGrady 2010 \\
11 FIP study 2000b & 23 NESDA study 2004-2007 \\
\hline
\end{tabular}

11 FIP study 2000b

23 NESDA study 2004-2007 